\title{
Observations of improvement of reaching in five subjects with left hemiparesis
}

\author{
Catherine A Trombly
}

\begin{abstract}
Kinematic analysis and surface electromyography were used to study reaching by five subjects with left hemiparesis as they attempted to touch each of three targets. The targets were placed to require movement within and out of extensor synergy. Each subject was tested five times over a nine week period. Over this time, amplitude of peak velocity and sense of limb position significantly improved in the paretic arms. The increase of amplitude of peak velocity was more strongly related to a decrease in the discontinuity of movement $(r=-0.48)$ than to maximal level of contraction of the prime movers (anterior deltoid: $r=0.25$; biceps: $r=0.39$ ). This finding may be a sign of learning or increased maturity of reach. These results, if replicated in a larger sample, would support therapy designed to improve learning of new sensorimotor relationships in the hemiparetic limb.
\end{abstract}

(F Neurol Neurosurg Psychiatry 1993;56:40-45)

Many hours of therapy time are devoted to improving motor control for stroke patients; however, success has been limited. ${ }^{1-2}$ Lack of knowledge about the natural history of recovery of voluntary movement has been proposed as a reason for limited success. ${ }^{1-5}$ Longitudinal and cross-sectional studies that used behavioural observations of motor task performance $^{6-8}$ have not produced specific enough information to guide remediational therapy of patients with stroke and abnormal motor control. Instrumentation that can provide that specificity has recently been used to examine movement of the affected arm of hemiparetic subjects.

Wing et $\mathrm{al}^{9}$ used electrogoniometry of elbow and shoulder joints and electromyography (EMG) of biceps and triceps. They studied recovery of two-dimensional (XY) reaching in the affected arms of five heterogenous hemiparetic patients. Over a 12 month period, four of the stroke subjects recovered amplitude of peak velocity to a level $85 \%$ of that of their unaffected arms and $50 \%$ of that of one normal control subject. The authors attributed the improvement to reduced pre-movement co-contraction of the biceps and triceps, but the electromyographical aspect of their study was not well described.

Lough et $a l^{3}$ used electrogoniometry and videotape analysis to examine changes in ability to reach directly forward by a 26 year old male who had suffered a cerebrovascular accident in the right hemisphere two weeks before the start of the study. Over the 10 week recording period, the path of the hand to target became more smooth and direct; the peak and mean velocities increased; and, reciprocally, movement time decreased. The authors attributed those changes to improved force, although they did not measure force production or muscular contraction to verify that supposition. Brooks and Watts ${ }^{10}$ reported similar changes in quality of reaching by monkey subjects; however, they explained the changes as being secondary to learning. It is important for therapists to know not only what characteristic of reaching improves, but also whether the improvement is associated more with increased muscle activity or with learning, because each mechanism would indicate a different treatment approach.

The present study extends the work of Wing et $a l^{9}$ and Lough $e t a l^{3}$ by measuring reaching in three-dimensions, a more natural situation. Both electromyographic and kinematic data were collected to answer the following questions:

(1) Does amplitude of peak velocity significantly increase over a two month laterehabilitation period in these left hemiparetic subjects?

(2) Is there an association between amplitude of peak velocity and level of muscle activity or smoothness of movement?

(3) What other measured variables improve concomitantly over the same time period?

\section{Method}

Subjects

After giving informed consent, five left hemiparetic subjects participated in the study. Subject characteristics are listed in table 1 . Additionally, all subjects had been employed before their stroke and all expected to be reemployed. No subject was reported by therapists to be apraxic. None had left-sided neglect as measured by the Shenkenberg line bisection test ${ }^{11}$, therefore none was expected to have difficulty in locating the targets in space. All subjects received payment for their continued participation.

\section{Instrumentation}

Electromyography The anterior deltoid, biceps, clavicular portion of the pectoralis major and lateral head of the triceps were monitored using surface electromyography. The EMG signals were differentially amplified 
Table 1 Patient characteristics

\begin{tabular}{|c|c|c|c|c|c|c|c|c|}
\hline Subject & Age & Sex & $\begin{array}{l}\text { Hand } \\
\text { dominance }\end{array}$ & $\begin{array}{l}\text { No. weeks } \\
\text { post-stroke* }\end{array}$ & Lesiont & $F M M T^{*}$ & Spasticity* ${ }_{+}^{\star+}$ & Sensation $\approx$ \\
\hline 1 & 42 & $\mathrm{~F}$ & $\mathbf{R}$ & $22 \cdot 3$ & $\begin{array}{l}\text { Haemorrhage of lenticular nucleus } \\
\text { and corona radiata }\end{array}$ & 17 & 12 & 10 \\
\hline 2 & 60 & F & $\mathbf{R}$ & $12 \cdot 3$ & $\begin{array}{l}\text { Lacunar infarct of lenticular } \\
\text { nucleus }\end{array}$ & $25 \cdot 5$ & 6 & 11 \\
\hline 3 & 64 & $\mathbf{F}$ & $\mathbf{R}$ & $12 \cdot 0$ & $\begin{array}{l}\text { Lacunar infarct of internal capsule } \\
\text { and cerebral atrophy }\end{array}$ & 18 & 0 & 18 \\
\hline 4 & 36 & $\mathbf{F}$ & $\mathbf{R}$ & $16 \cdot 0$ & $\begin{array}{l}\text { Cerebellar hemispheric infarct } \\
\text { with brainstem involvement }\end{array}$ & 32 & 0 & 15 \\
\hline 5 & 57 & $\mathbf{M}$ & $\mathrm{L}$ & $9 \cdot 5$ & Cerebellar hemispheric infarct & 36 & 0 & 12 \\
\hline
\end{tabular}

${ }^{\star}$ First testing period. †As recorded in medical record. FMMT $=$ Fugl-Meyer motor function test, ${ }^{8}$ upper limb subtest $36=$ control of individual movements of the proximal upper extremity.

tResistance to passive stretch of all arm motions was estimated on a 4-point scale from immovable to normal using the modified thesistance to passive stretch of all arm motions was estimated on a normal awareness $=18$.

using a Grass Model 7 polygraph (Grass Instrument Company, Quincy, Massachusetts) and digitised on line using WATScope ${ }^{\mathrm{TM}}$ (Northern Digital, Waterloo, Ontario) digital converter and data acquisition software at a sampling rate of $500 \mathrm{~Hz}$. The data were processed and analysed off line using ANAPAC waveform analysis package (Run Technologies, Laguna Nigel, California). Processing consisted of linear digital filtering, rectification, and integration.

Kinematic recording. The Waterloo spatial analysis and recording technique (WATSMART $^{\mathrm{TM}}$, version $2 \cdot 7$, a non-contact, optoelectric system was used to track an infrared light-emitting diode attached to the base of the index finger. The instantaneous position of the diode was monitored by two infrared sensors mounted approximately $1.5 \mathrm{~m}$ above the seated subject. A computer (Hewlett-Packard, Waltham, Massachusetts) controlled the strobing of the diode as well as data acquisition. The position of the diode was digitised at a rate of $100 \mathrm{~Hz}$ and these data were stored for off line analysis. To reduce the likelihood of error due to reflected light, the room and target supports were painted with infrared absorbing black paint and the subject and table were draped with black cloth. ${ }^{14}$ Before each experiment with each arm, the sensors were calibrated in relation to the test area. Maximum accepted error was $2.0 \mathrm{~mm}$; average error was $1.73 \mathrm{~mm}$ (SD 0.26).

Experimental set-up Multiple targets were used because experience and the literature ${ }^{67}$ indicated that stroke survivors at various stages of recovery have limited ability to move freely, especially outside of stereotyped synergy patterns. Each of the three targets was a $7.6 \mathrm{~cm}$ circle mounted on a shoulder-high standard. All were equidistant from the subject's hand. Target 1 was placed to require only movement within extensor synergy (shoulder adduction and elbow extension). ${ }^{6}$ Target 2 required reaching directly forward, a movement requiring beginning combination of flexion and extension synergies. ${ }^{6}$ Target 3 required movement free of synergy (shoulder abduction coupled with elbow extension). Light-emitting diode displays, positioned above each target, reminded the subject which target he or she was aiming for. Data collection started automatically with activation of the display. Start of reach was signalled by a microswitch located under the subject's hand. End of reach was signalled by a microswitch which responded to touch anywhere on the target. The output from all microswitches was processed through the WATScope ${ }^{\text {TM }}$ A/D converter and software. Subject 1 was unable to touch any of the targets during the early visits, so end of reach was determined as the least distance between the diode on her hand and diodes on the targets.

According to Fitts' Index of Difficulty ${ }^{15}$, the reaching task is rated as $3 \cdot 70$, which classifies it as an open loop task (4.58 or less). ${ }^{16}$ We would expect, therefore, to see reaches consisting of one continuous movement, which is the shared strategy of normal, mature humans and monkeys when reaching to touch a large target. $^{101718}$

\section{Procedure}

Each subject was tested five times, approximately once every two weeks. No attempt was made to control for outpatient therapy or involvement in daily tasks. At each visit, clinical measures were taken before application of the electrodes or diodes (see table 1).

The subject sat with the shoulder of the arm to be tested directly in line with target 2 and the hand resting on the start pad at the edge of the table. Subjects knew which target to aim for before each trial and were instructed to begin reach when the display above the particular target illuminated. The subject completed three trials to each target before reaching to the next one. Significant learning was not expected within so few trials. ${ }^{19}$

\section{Data reduction}

Scores were derived from the raw data using the following procedures. The EMG values for each muscle during reach were normalised in relation to maximum voluntary contraction and reported as \%MVC. MVC refers to the amount of electrical activity generated by a muscle during a maximum isometric control contraction done with the muscle in shortened range. Coactivity ratios were calculated for the biceps and triceps, for the anterior deltoid and biceps, and for the anterior deltoid and pectoralis major using the formula of Hammond $e t$ $a .^{20}$

The two-dimensional kinematic data were converted to three-dimensional coordinates using a direct linear transformation algorithm $^{14}$ and filtered at $5 \mathrm{~Hz}$. Values for the speed of the endpoint, here referred to as 
"velocity", and rate of change of speed, here referred to as "acceleration", were obtained for every $0.01 \mathrm{~s}$ from the WATSMART ${ }^{\mathrm{TM}}$ processed files using a custom-written program. The terms velocity and acceleration are used in order to be congruent with the literature. Speed and rate of change of speed are scalar, not vector, quantities, however, and as such, describe movement in three dimensions simultaneously as was the case in this study.

From these files, the variables derived for each reach were: amplitude of peak velocity; time to peak velocity; smoothness of movement (number of steps ${ }^{21}$ or movement units $^{22}$ ); and percentage of first movement unit at which peak velocity occurred.

Data analysis The data were grouped for analysis. Given the low number of subjects and expected variability among them, ${ }^{19}$ this was a conservative approach chosen to discern general effects that would be useful for guiding therapy and would offer insight into the reorganisation of voluntary movement of left hemiparetics. The non-parametric Friedman two-way analysis of variance (subject $\times$ condition) for related samples was used. ${ }^{23}$ The resulting statistic was distributed $\chi_{r}^{2}$. Relationships among variables were examined using averaged correlations. ${ }^{24}$

\section{Results}

Subject 1 lacked endurance to attempt more than six reaches on the first visit; otherwise all subjects were able to reach towards all three targets on all visits, regardless of clinical motor control score. Control of reaching generally improved for subjects $1,2,4$ and 5 , but subject 3's performance deteriorated over time. The results reported here include all subjects, unless noted.

The only significant difference among targets was due to the biomechanical demands of the target locations, that is, the pectoralis major/anterior deltoid co-activity ratio (PM) AD) significantly decreased $\left(\chi_{r}^{2}=8 \cdot 4\right.$, $\mathrm{df}=2, \mathrm{p}<0.02$ ) between targets 1 and 3 .
This indicates that the pectoralis major was less active relative to the anterior deltoid for target 3, which required shoulder abduction, compared with target 1 , which required shoulder horizontal adduction. All scores were collapsed across targets for further analysis.

In the non-affected arm, reaching performance was essentially normal ${ }^{18}$ and did not change significantly over the course of the study.

One clinical variable, awareness of limb position, improved significantly $\left(\alpha_{r}^{2}=9 \cdot 64\right.$, $\mathrm{df}=4, \mathrm{p}<0.05$ ) over time (fig 1). In the affected arm, amplitude of peak velocity also improved significantly $\left(\chi_{r}^{2}=10 \cdot 72, \mathrm{df}=4\right.$, $\mathrm{p}<0.05$ ) over the five visits (fig 2).

The location of peak velocity within the first movement unit was about normal $(\sim 50 \%)$ (fig 2 ). Over the five visits, time to peak velocity also became more normal as described by Wing and Miller. ${ }^{25}$ The number of movement units decreased, especially between visits 2 and 3 (fig 2). When Subject 3's scores are eliminated, the decrease is marginally significant $\left(\chi_{r}^{2}=9 \cdot 0, \mathrm{df}=4, \mathrm{p}<0 \cdot 10\right)$. There is reason to exclude her scores because, although the clinical evaluations indicated normal tone and awareness of limb position and ability to move the arm voluntarily within limited patterns, her performance became more erratic over the course of the study, perhaps because of her secondary diagnosis of cerebral atrophy.

MVC, \%MVC, and co-activity scores did not improve significantly across visits.

As amplitude of peak velocity increased, both movement time and number of movement units decreased (table 2). There were positive, but weak, relationships between amplitude of peak velocity and maximum contraction of the anterior deltoid, biceps and triceps. The \%MVC of the anterior deltoid, the prime mover, ${ }^{26} 27$ was positively, moderately related to increased amplitude of peak velocity over the five visits. Similarly, the relationship between amplitude of peak velocity and the PM/AD co-activity index indicated that as the peak velocity increased, the anterior deltoid became more active relative to the pectoralis major.

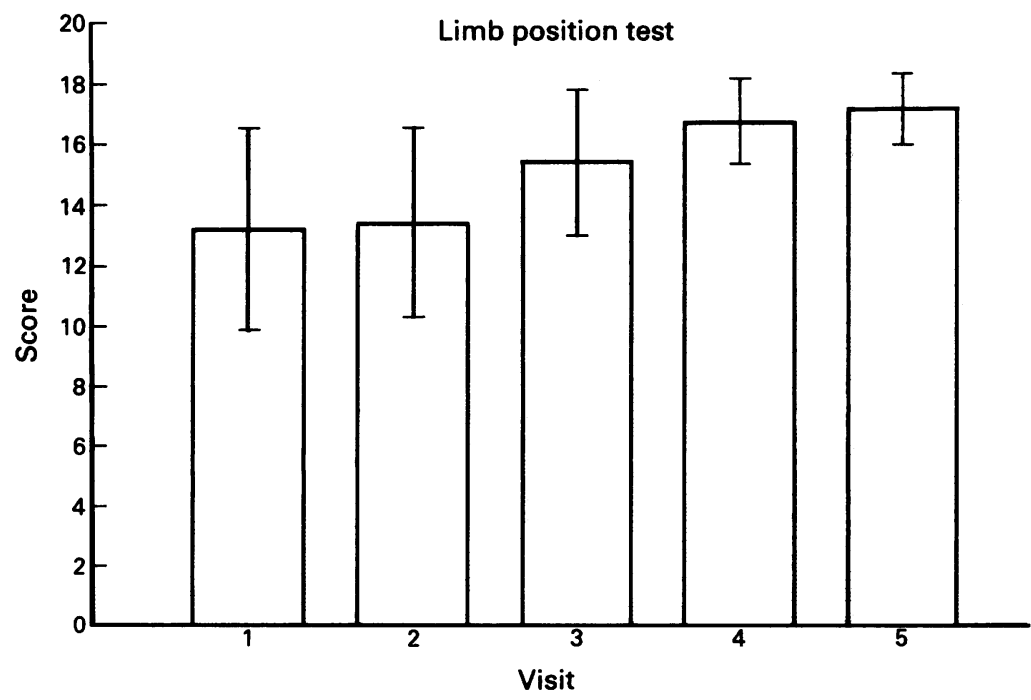

Figure 1 Mean and standard deviation: test of awareness of limb position.
Table 2 Average correlations * with amplitude of peak velocity of the affected arm

\begin{tabular}{lr}
\hline Movement time & -0.63 \\
Movement units & -0.48 \\
MVC (control contraction) + & 0.25 \\
Anterior deltoid & 0.07 \\
Pectoralis major & 0.39 \\
Biceps & 0.30 \\
Triceps & \\
\% MVC & 0.49 \\
Anterior deltoid & -0.34 \\
Pectoralis major & 0.16 \\
Biceps & 0.07 \\
Triceps & \\
Coactivity & -0.01 \\
Biceps/Anterior deltoid & -0.49 \\
Pectoralis major/Anterior deltoid & -0.07 \\
Triceps/biceps &
\end{tabular}

*The average scores ( 3 trials $\times 3$ targets) of each visit of each subject were correlated across visits. The Pearson Product Moment correlation coefficients related to each subject were then converted to Fisher's $Z$, averaged across subjects, and then converted to Fisher's $Z_{r}$, averaged across subjects, and
reconverted to $r^{24}$ No coefficient reached critical value of 0.878 $(a=0.05, \mathrm{df}=3)$

tOne score per subject per visit.

MVC = Maximum voluntary contraction. 
Figure 2 Means and standard deviations of kinematic variables.
Kinematic variables

Time to peak velocity

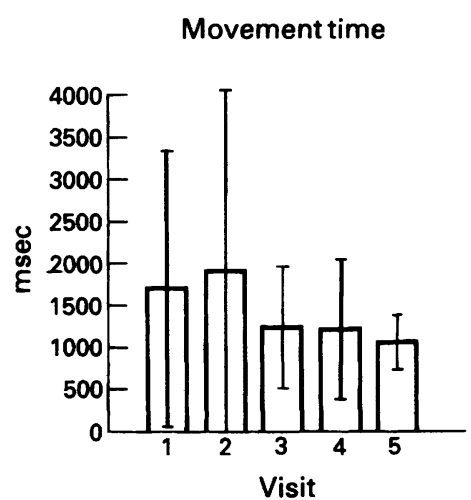

\section{Discussion}

This study supports the finding of the previous two studies ${ }^{39}$ that amplitude of peak velocity increased over time in subjects after a stroke. In the present study, movement time decreased concomitantly with improved peak velocity, as observed by Lough et $a l^{3}$. The location of the peak at a normal point in the velocity profiles ${ }^{28}$ of the first movement unit suggests that the motor plan was preserved in the affected arm. It was ineffective, however, possibly because of weakness or disturbance in sensory motor relationships.

The improvement in amplitude of peak velocity of these subjects does not seem to be associated with increased strength. The electrical activity generated by the prime movers during maximum isometric contraction showed no trend of improvement over the five visits. This was true even though two of the subjects were engaged in weight-lifting programmes. There was a trend towards use of a greater percentage of the available activity of the anterior deltoid during the unrestricted reaching task over the course of the study. These findings seem to contradict the suggestions of Lough et $a l^{3}$ and Wing et $a l^{9}$ that increased amplitude of peak velocity is associated with greater force or reduced biceps/ triceps co-contraction. Further examination of these relationships in a larger sample of subjects is warranted.

Learning is an alternate explanation for increased amplitude of peak velocity. Brooks and Watts ${ }^{10}$ found increased amplitude of peak velocity to be related to learning the strategy of smooth, direct reaching in normal monkeys, that is, peak velocity increased as the monkeys changed from discontinuous (closed loop,

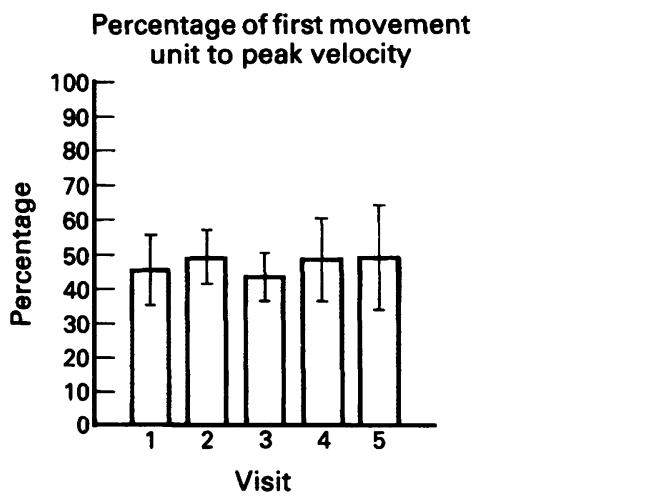

non-programmed) movement to continuous ${ }^{102129}$ (open loop, programmed) movement. The subject in the study by Lough et $\mathrm{al}^{3}$ seemed to undergo similar learning: he changed his performance from indirect, discontinuous movement during the early weeks to direct, continuous movement in the later weeks. Wing et $a l^{9}$ did not report information related to this possibility. Although the present study was deliberately designed to make motor learning unlikely ${ }^{19}$, four out of five subjects learned to move their affected arm more smoothly despite the lack of change in levels of muscular activity. It seems that the subjects of this study were learning, with very little practice, to apply old programmes to the new conditions of weakness and sensory disturbances. $^{30}$

From the acceleration and velocity traces (fig 3), for example, it appears that the subjects of the present study experimented with strategies that sometimes resulted in smoother, more programmed reaches and at other times resulted in discontinuous, sensory-guided reaches. A similar "trying out" of guided and programmed strategies was seen in monkey ${ }^{10}$ subjects and in children ${ }^{31}$ as they learned simple reaching tasks. Programmed and guided modes of control are normally integrated in adults and older children who use each selectively as the situation warrants. ${ }^{31-33}$ However, this level of control is learned. Not only are the two modes of motor control not integrated during childhood, but the predominance of one system over the other changes with maturity. ${ }^{31}$ Ballistic, triggered movement is replaced by guided control of a movement response which, in turn, is supplanted by programmed control and finally, integration of 
Figure 3 Examples of velocity profiles and acceleration traces of reaches to target 2 by subject 2. Note the shifts between discontinuous (visits 1 and 5) and more continuous strategies (visit 3).
Visit 1
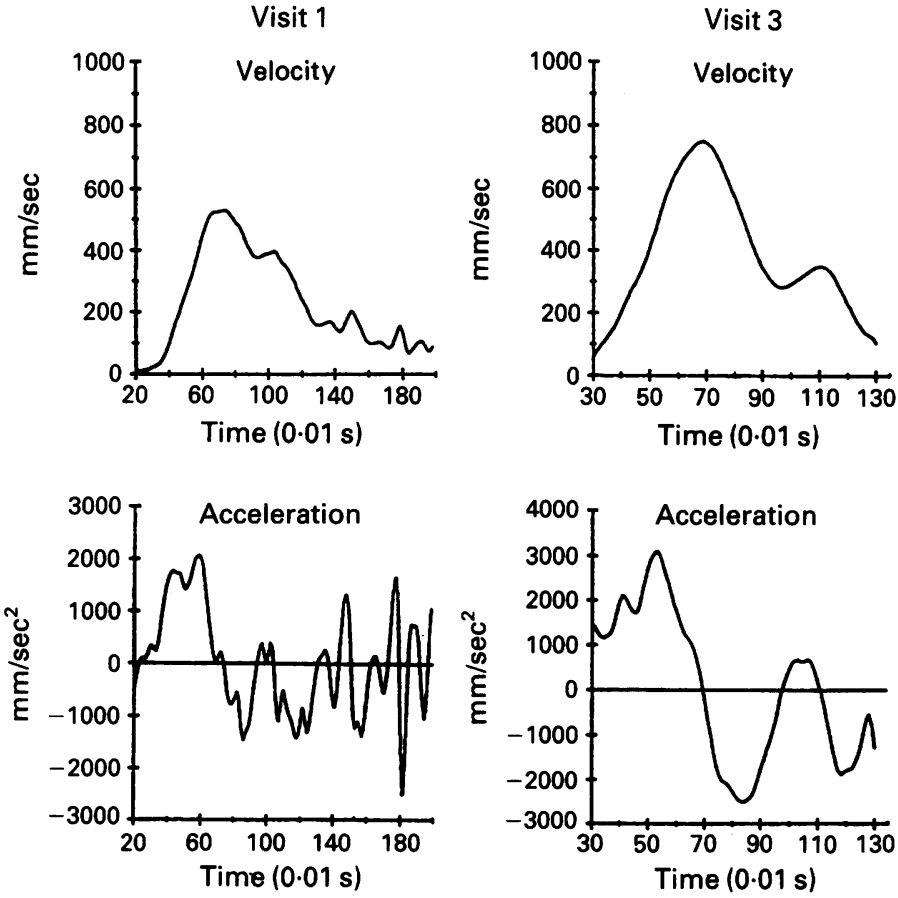

Visit 5
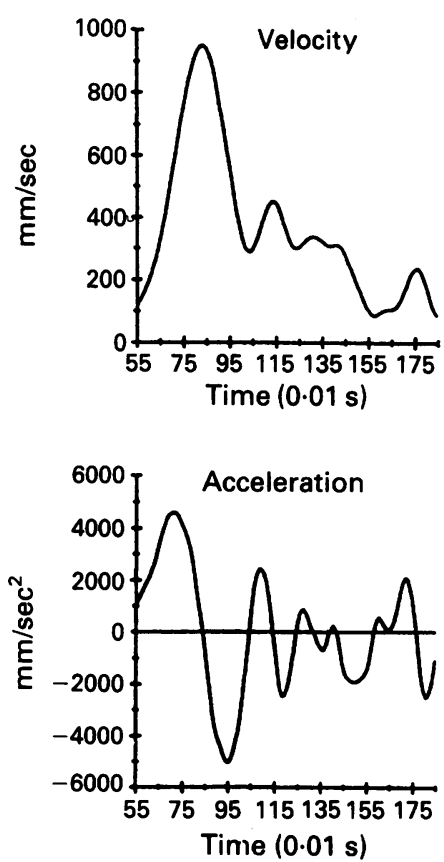

guided and programmed modes of control occurs. $^{313234}$ This developmental sequence from guided to programmed modes was apparent in four of the subjects. However, subject 3 showed the reverse: the programmed mode deteriorated to guided and then to ballistic, triggered type control mode. ${ }^{28}$

Scores of variables indicative of coordinated motor control (speed and smoothness) were not significantly different among targets. Even subject 1, who was rated by the Fugl-Meyer motor function test as being in flexor synergy, was able to move towards all three targets as soon as she had the endurance to complete the experiment. This finding is contrary to expectation based on Brunnstrom's ${ }^{6}$ sequence of recovery of voluntary arm movement.

\section{Conclusions}

Earlier findings ${ }^{3910}$ were confirmed: amplitude of peak velocity improved over time in a way not attributable to chance. Because this occurred during a post-rehabilitation period when little improvement is expected, it seems that amplitude of peak velocity could serve as a sensitive outcome variable for use in future studies of effectiveness of intensive therapy to remediate motor control deficits of stroke patients.

Level of muscular activity did not improve, but the discontinuity of movement decreased (guided control became programmed control $^{2129}$ ) over the nine-week test period in four of the five subjects. It appears that the increase in amplitude of peak velocity seen in these subjects was related more to learning than to improved muscle activation. If this observation is confirmed in future studies, then therapy that provides the opportunity for relearning sensorimotor relationships would be warranted for patients similar to the subjects in this study.

The level and pattern of muscle activity of these subjects depended on the biomechanical demands of the task rather than any stereotyped neurological linkage between muscles. This finding would not support a treatment approach for these subjects in which developmental principles, such as movement within synergy pattern preceding movement outside of synergy pattern, are applied.

I am particularly grateful to the five subjects who completed the study. I want to recognise the cooperation of Spaulding Rehabilitation Hospital, Boston, Massachusetts; Braintree Hospital, Braintree, Massachusetts; and New England Rehabilitation Hospital, Woburn, Massachusetts and the assistance of $K$ Ramesh Murthy, and Michael Baker.

Funding for this study was provided through a Mary E. Switzer Distinguished Fellowship Award from the National Institute on Disability and Rehabilitation Research. The study was conducted under the auspices of the Center for Scholarship and Research at Boston University funded by the American Occupational Therapy Association and the American Occupational Therapy Foundation.

1 Basmajian JV, Gowland CA. The many hidden faces of stroke: A call for action. Arch Phys Med Rehab 1987; 68:319.

2 Basmajian JV. The winter of our discontent: Breaking intolerable time locks for stroke survivors. Arch Phys Med Rehab 1989;70:92-4.

3 Lough S, Wing AM, Fraser C, Jenner JR. Measurement of recovery of function in the hemiparetic upper limb following stroke: A preliminary report. Hum Movement Sci 1984;3:247-56

4 Parker VM, Wade DT, Langton Hewer R. Loss of arm function after stroke: Measurement, frequency, and recovery. Int $\mathcal{F}$ Rehab Med 1986;8:69-73.

5 Dombovy ML, Bach-y-Rita P. Clinical observations on recovery from stroke. In: Waxman SG, ed. Advances in neurology, Vol. 47: Functional recovery in neurological disease. New York: Raven Press, 1988:265-312.

6 Brunnstrom S. Movement therapy in hemiplegia. New York: Harper and Row, 1970.

7 Twitchell TE. The restoration of motor function following hemiplegia in man. Brain 1951;74:443-80.

8 Fugl-Meyer AR, Jaasko LI, Olsson S, Steglind S. The post stroke hemiplegic patient: I. A method for evaluation of stroke hemiplegic patient: I. A method for evaluation of
physical performance. Scand $\mathcal{F}$ Rehab Med 1975;7:

9 Wing AM, Lough S, Turton A, Fraser C, Jenner JR Recovery of elbow function in voluntary positioning of the hand following hemiplegia due to stroke. 7 Neurol hand following hemiplegia due to
Neurosurg Psychiatry 1990;53:126-34.

10 Brooks VB, Watts SL. Adaptive programming of arm movement. $\mathcal{F}$ Motor Behav 1988:2:117-32.

11 Schenkenberg T, Bradford DC, Ajax, ET. Line bisection and unilateral visual neglect in patients with neurological impairment. Neurology 1980;30:509-17.

12 Bohannon RW, Smith MD. Interrater reliability of a 
modified Ashworth Scale of muscle spasticity. Phys Ther 1987;67:206-7.

13 Leo K, Soderberg G. Relationship between perception of joint position sense and limb synergies in patients with hemiplegia. Phys Ther 1981;61:1433-7.

14 Scholz J. Reliability and validity of the WATSMART ${ }^{\mathrm{TM}}$ three-dimensional optoelectric motion analysis system. Phys Ther 1989;69:679-89.

15 Fitts PM. The information capacity of the human motor system in controlling the amplitude of movement. $\mathcal{F} \operatorname{Exp}$ Pystem in controlling the $1954 ; 47: 381-91$.

16 Wallace SA, Newell KM. Visual control of discrete aiming movements. Quart $\mathcal{f}$ Exp Psychol 1983;35A:311-21.

17 Arbib MA. Schemas for the temporal organization of behaviour. Hum Neurobiol 1985;4:63-72.

18 Georgopoulos AP. On reaching. Ann Rev Neurosci 1986; 9:147-70.

19 Vorro JS, Hobart D. Kinematic and myoelectric analysis of skill acquisition: I. $90 \mathrm{~cm}$ subject group. Arch Phys Med Rehab 1981;62:575-82.

20 Hammond MC, Fitts SS, Kraft GH, Nutter PB, Trotter MJ, Robinson LM. Co-concentration in the hemiparetic forearm: Quantitative EMG evaluation. Arch Phys Med Rehab 1988;69:348-51.

21 Brooks VB, Cooke JD, Thomas JS. The continuity of movements. In: Stein RB, Pearson KG, Smith RS, Redford JB, eds, Control of posture and locomotion. New York: Plenum Press, 1973:257-72.

22 Fetters L, Todd J. Quantitative assessment of infant reaching movements. $\mathcal{f}$ Motor Behav 1987;19:147-66.

23 Siegel S. Nonparametric statistics for the behavioural sciences.
New York: McGraw-Hill, 1956.

24 Snedecor GW, Cochran WG. Statistical methods. 7th edn. Ames: Iowa State University Press, 1980.

25 Wing AM, Miller E. Research Note: Peak velocity timing invariance. Psychol Res 1984;46:121-7.

26 Basmajian JV, DeLuca CJ. Muscles alive: Their functions revealed by electromyography ( 5 th edn). Baltimore: Williams and Wilkins, 1985 .

27 Soechting JF, Lacquaniti F. Coordination of arm and wrist motion during a reaching task. Neurosci 1982;2: mog-408.

28 Nagasaki $H$. Asymmetric velocity and acceleration profiles of human arm movements. Exp Brain Res 1989;74: 319-26.

29 Brooks VB. Some examples of programmed limb movements. Brain Res 1974;71:299-308.

30 Winstein CJ. Motor learning considerations in stroke rehabilitation. In: Duncan PW, Badke MB, eds, Stroke rehabilitation: The recovery of motor control. Chicago: Year Book Medical Publishers, 1987:109-34.

31 Hay L. Spatial-temporal analysis of movements in children: Motor programs versus feedback in the development of reaching. F Motor Behav 1979;11:189-200.

32 Bushnell EW. The decline of visually guided reaching during infancy. Infant behaviour and development 1985; 8:139-55

33 Soechting JF, Lacquaniti F. Invarient characteristics of a pointing movement in man. $\mathcal{f}$ Neurosci $1981 ; 1: 710-20$.

34 Van Hofsten C. Development of visually directed reaching: The approach phase. $\mathcal{f}$ Hum Movement Stud 1979;5: 160-78.

\section{John Locke and the trigeminal neuralgia of the Countess of Northumberland}

Although early descriptions of tic douloureux can be inferred from the writings of Avicenna, the most convincing early description was of the suffering physician and philosopher Johannes Laurentius Bausch (1605-65) described by Drs JM Fehr and Elias Schmidt in volume 2 of the published proceedings of the Imperial Leopoldinian Academy of Natural Sciences in $1671 .^{1}$ Of the English contributions, John Locke the famous physician and philosopher described the condition in a series of letters to Dr John Mapletoft in $1677 .^{2}$ The unfortunate patient was the Countess of Northumberland, wife of the Ambassador to France:

Paris, 4th December, 1677

“... On Thursday night last I was sent for to My Lady Ambassadice, whom I found in a fit of such violent and exquisite torment that ... it forced her to such cries and shrieks as you would expect from one upon the rack, to which I believe hers was an equal torment, which extended itself all over the right side of her face and mouth. When the fit came, there was, to use My Lady's own expression of it, as it were a flash of fire all of a suddaine shot into all those parts, and at every one of those twitches made her shreeke out, her mouth was constantly drawn on the right side towards the right eare by repeated convulsive motions ... These violent fits terminated on a suddaine, and then My Lady seemed to be perfectly well ... Speaking was apt to put her into these fits; sometimes opening her mouth to take anything, or touching her gums, especially in places where she used to finde these throbings; pressing the side of her face by lying on it were also apt to put her in these fits. These fits lasted sometimes longer, sometimes shorter . . . at intervals between them not halfe an hower, commonly much shorter..."

Paris, 22 December, '77

"... I believe the drawing of those two teeth, especially the last, hath injur'd some nerve, and soe makes it very apt to be provoked, and draws its neighbours into consent; yet by what My Lady informed me, since violence of her pains have been over, I have reason to suspect there is an ancienter fault in the nerves of that side ..."

Later accounts by Wepfer, Nicolaus André (who called it tic douloureux), John and his nephew Samuel Fothergill, and later Charles Bell were to elaborate and elucidate some of the features, possible causes and treatments.

JMS PEARCE

1 Lewy FH. The first authentic case of major trigeminal neuralgia and some comments on the history of this disease. Ann Med Hist 1938;10:247-50.

2 Dewhurst $K$. A symposium on trigeminal neuralgia with contributions by Locke, Sydenham, and other eminent seventeenth century physicians disease. Ann f Hist Med 